\title{
Significance of Circulating Galectin-3 in Patients with Pancreatobiliary Cancer
}

\author{
TATSUO SHIMURA ${ }^{1}$, MASAHIKO SHIBATA $^{2}$, KENJI GONDA ${ }^{2}$, YASUHIDE KOFUNATO ${ }^{1}$, RYO OKADA $^{1}$, \\ TERUHIDE ISHIGAME ${ }^{1}$, TAKASHI KIMURA ${ }^{1}$, AKIRA KENJO ${ }^{1}$, KOJI KONO ${ }^{1}$ and SHIGERU MARUBASHI \\ ${ }^{1}$ Department of Hepato-Biliary-Pancreatic and Transplant Surgery, and \\ ${ }^{2}$ Department of Gastrointestinal Tract Surgery, Fukushima Medical University, Fukushima, Japan
}

\begin{abstract}
Background/Aim: Pancreatobiliary cancer is a disease associated with a dismal prognosis and limited treatment options. The aim of the present study was to clarify the usefulness of circulating galectin-3 in pancreatobiliary cancer. Patients and Methods: We examined serum galectin3 concentrations in 45 patients with pancreatobiliary cancer. Receiver operating characteristic curves were utilized to evaluate the accuracy of circulating galectin-3 to discriminate pancreatobiliary cancer patients from controls and predict the prognostic outcomes. Results: Circulating galectin-3 had diagnostic value at the cut-off level of $6.2 \mathrm{ng} / \mathrm{ml}$, and the patients' overall survival was predictable at the cut-off level of $10.3 \mathrm{ng} / \mathrm{ml}$. Furthermore, circulating galectin-3 $\geq 10.3 \mathrm{ng} / \mathrm{ml}$ was an independent prognostic marker in pancreatobiliary cancer. Regarding biliary cancer, higher galectin-3 was associated with malnutrition. On the other hand, regarding pancreatic cancer, higher galectin-3 levels were associated with higher inflammatory parameters. Conclusion: Galectin-3 can be a useful biomarker in patients with pancreatobiliary cancer.
\end{abstract}

Pancreatobiliary cancer is associated with a dismal prognosis and limited treatment options (1). Detection of this cancer is often difficult because it lacks clinical manifestation. Pancreatic cancer is the fourth most-common cause of cancer-related death in the United States, with an estimated 53,070 new cases and 41,780 deaths in 2016 (2). Cancers of the extrahepatic biliary tract and gallbladder are relatively less common in the United States, with an estimated 11,420

Correspondence to: Tatsuo Shimura, MD, Ph.D., Department of Hepato-Biliary-Pancreatic and Transplant Surgery, Fukushima Medical University, 1 Hikarigaoka, Fukushima, Fukushima 9601259, Japan. Tel: +81 245471111, e-mail: tshimura@fmu.ac.jp

Key Words: Galectin-3, interleukin-6, intercellular adhesion molecule-1, malnutrition. new cases and 3,710 deaths in 2016 (2). In Japan, however, cancers of the extrahepatic biliary tract and gallbladder are more common, with an estimated 18,152 deaths in 2015 (3). Thus, to detect pancreatobiliary cancer in its early phase and estimate prognosis for deciding the necessity of adjuvant therapy, the discovery of a biomarker is important.

Galectins are a family of carbohydrate-binding proteins characterized by conserved amino acid sequences of their carbohydrate-binding domains and affinity for beta-galactosidecontaining glycoconjugates (4). Galectin-3, also known as Mac-2, has been implicated in cell growth, differentiation, apoptosis, adhesion, malignant transformation, RNA processing and angiogenesis (4-9).

Cytoplasmic galectin-3 acts as an apoptosis inhibitor in the cytoplasm and, in certain conditions, regulates trafficking between the cytoplasm and the nucleus (6). Nuclear galectin-3 has been reported to function as an mRNA splicing promoter (9). When expressed on the surface of tumor cells, galectin-3 plays a role as an adhesion molecule in cell-to-cell or cell-to-matrix interactions (10). Circulating galectin-3 has been reported to be produced by activated macrophages, mast cells and eosinophils, as well as tumor cells (11).

Recent studies have revealed that there are elevated concentrations of serum galectin-3 in various cancers including melanoma $(12,13)$, breast (12), ovarian (12), colorectal $(14,15)$, stomach $(16)$, lung $(12)$, bladder $(17,18)$, head and neck (19), liver (20), thyroid (21, 22), and pancreatic cancers (23). These studies demonstrated higher amounts of galectin-3 in the sera of their patients and its association with poorer prognosis. However, the significance of circulating galectin-3 as a biomarker in pancreatobiliary cancer has yet to be elucidated.

The aim of the present study was to clarify the relationships between circulating galectin-3 and inflammatory or nutritional parameters. We also investigated the overall survival of patients according to their circulating galectin-3 levels. 


\section{Patients and Methods}

Patients. Blood samples were collected from 45 patients with pancreatobiliary cancer between April 2011 and March 2013 before starting treatment. Sera from patients were stored at $-80^{\circ} \mathrm{C}$ until use. The patients included 24 biliary cancer patients (stage I:IIA: IIB:III=7:8:7:2) and 21 pancreatic cancer patients (stage IA:IB:IIA:IIB:III=2:1:9:7:2). The final stage of the patients was determined pathologically according to the TNM classification system of malignant tumors published by the International Union Against Cancer, 8th edition (24). The enrolled patients underwent surgery for treatment of histologically confirmed cancers at our department. In addition, blood samples from 35 healthy volunteers (median age $=55$ years, range $=25-84$ years, 20 males and 15 females) were used as controls. A mean observation period for the 45 patients was 28.4 months (range=1.6-69.9), while mean observation periods for the 24 biliary cancer patients and the 21 pancreatic cancer patients were 38.7 (range=1.6-69.9) and 23.5 (range=2.5-66.0) months, respectively. The final assessment of patients' survival was made on May 22, 2017. The study protocol was approved by the ethics committee of Fukushima Medical University and written informed consent was obtained from the enrolled patients and healthy volunteers.

Measurements of galectin-3 and parameters. Serum concentrations of galectin-3 were measured using an enzyme-linked immunosorbent assay (ELISA; R\&D Systems, Minneapolis, MN, USA) according to the manufacturer's instructions. Patients' nutritional statuses were determined by measuring the serum concentrations of albumin, retinol binding protein (RBP), transthyretin (TTR) and transferrin (TF). C-reactive protein (CRP), neutrophil count, lymphocyte counts, monocyte count, as well as neutrophil-to-lymphocyte ratio (NLR) and lymphocyte-to-monocyte ratio (LMR), were used as indicators of inflammation. Usefulness of circulating galectin-3 as a tumor marker was assessed by comparison with serum levels of carcinoembryonic antigen (CEA) and carbohydrate antigen 19-9 (CA19-9).

Statistical analysis. Differences between continuous variables were analyzed using the Mann-Whitney $U$-test. Differences between categorical variables were analyzed using the chi-square test or Fisher's exact test when appropriate. Overall survival rate was calculated using the Kaplan-Meier method, and was statistically analyzed using a log-rank test. A Cox proportional hazard model was used to identify prognostic factors. Receiver operating characteristic (ROC) curves were utilized to evaluate the accuracy of circulating galectin-3 to discriminate pancreatobiliary cancer patients from controls and to predict the good and poor outcomes. A $p$-value $<0.05$ was considered statistically significant. All statistical calculations were performed using SPSS $^{\circledR}$ version 24 (IBM Japan, Tokyo, Japan). Not all blood samples were of sufficient volume for all measurements.

\section{Results}

Levels of circulating galectin-3. The levels of circulating galectin-3 of the total patients, patients with biliary cancer, and patients with pancreatic cancer, were significantly higher than those of healthy volunteers $(p<0.001)$. However, there was no significant difference between the TNM stages of the diseases (Figure 1). We next examined the performance of circulating galectin-3 as a tumor marker using a ROC curve. At the cutoff level of $6.2 \mathrm{ng} / \mathrm{ml}$, circulating galectin-3 had diagnostic value for pancreatobiliary cancer [area under the curve $=0.795,95 \%$ confidence intervals $(\mathrm{CI})=0.698-0.892$, $p<0.001]$. Thereafter, a sensitivity, a specificity, a positive predictive value, and a negative predictive value were $88.9 \%, 60.0 \%, 74.1 \%$, and $80.8 \%$, respectively. Sensitivity could be improved by using galectin-3 with CEA and CA199 (Table I).

Relationship between overall survival and circulating galectin-3. When analyzing a ROC curve using patient death as a determiner, circulating galectin-3 levels were able to predict the patients' overall survival (area under the curve $=0.732, \quad 95 \% \mathrm{CI}=0.583-0.882, \quad p=0.008) \quad$ with a sensitivity of $70.8 \%$ and specificity of $71.4 \%$ at the cutoff level of $10.3 \mathrm{ng} / \mathrm{ml}$. We then divided our patients into two groups: a low galectin-3 group (circulating glaectin-3 levels $<10.3 \mathrm{ng} / \mathrm{ml}$ ) and a high galectin-3 group (circulating glaectin-3 levels $\geq 10.3 \mathrm{ng} / \mathrm{ml}$ ). Figure 2 shows the overall patient survival rates. The high galectin- 3 groups showed poorer prognoses than the low galectin-3 groups in both biliary and pancreatic cancer patients. Analyses using a Cox proportional hazard model are summarized in Table II. Circulating galectin-3 levels (galectin-3 $<10.3 \mathrm{ng} / \mathrm{ml} v s$. galectin-3 $\geq 10.3 \mathrm{ng} / \mathrm{ml})$, T category (T1+T2 vs. T3+T4), $\mathrm{N}$ category (negative $v s$. positive), TNM stage (Stage I+II $v s$. Stage III), and adjuvant chemotherapy (negative $v s$. positive) were examined as prognostic factors. A high galectin-3 level was an independent prognostic factor in both biliary and pancreatic cancer.

Subgroup analyses. The demographics of each group are summarized in Table III. In an analysis on all 45 patients, the incidence of those with $\mathrm{T} 3$ or T4 was statistically higher in the high galectin-3 group than in the low galectin-3 group $(p=0.045)$, and the incidence of patients with moderately or poorly differentiated adenocarcinoma was statistically higher in the high galectin-3 group ( $p=0.045)$. Figure 3 shows the inflammatory and nutritional parameters according to galectin-3 levels. With regard to biliary cancer, RBP (median $=1.5$, range $=0.6-1.9, p<0.001)$, TTR $($ median $=12.6$, range $=2.9-17.6, p<0.001)$, TF (median $=191.5$, range $=116$ $249, p=0.020$ ) and albumin (median $=3.1$, range $=1.8-3.8$, $p=0.001$ ) were found to be significantly lower in the high galectin-3 group than those (RBP: median $=2.1$, range $=1.7$ 4.7; TTR: median $=19.1$, range $=13.8-32.2$; TF: median $=209$, range $=186-342$; albumin: median $=3.8$, range $=2.7-4.5$ ) in the low galectin-3 group. On the other hand, regarding pancreatic cancer, neutrophil count (median $=75 \%$, range $=55-82 \%$, $p=0.029$ ) and NLR (median $=5.6$, range $=1.2-10.6, p=0.020$ ) were higher in the high galectin-3 group than those 
A

(ng/ml)

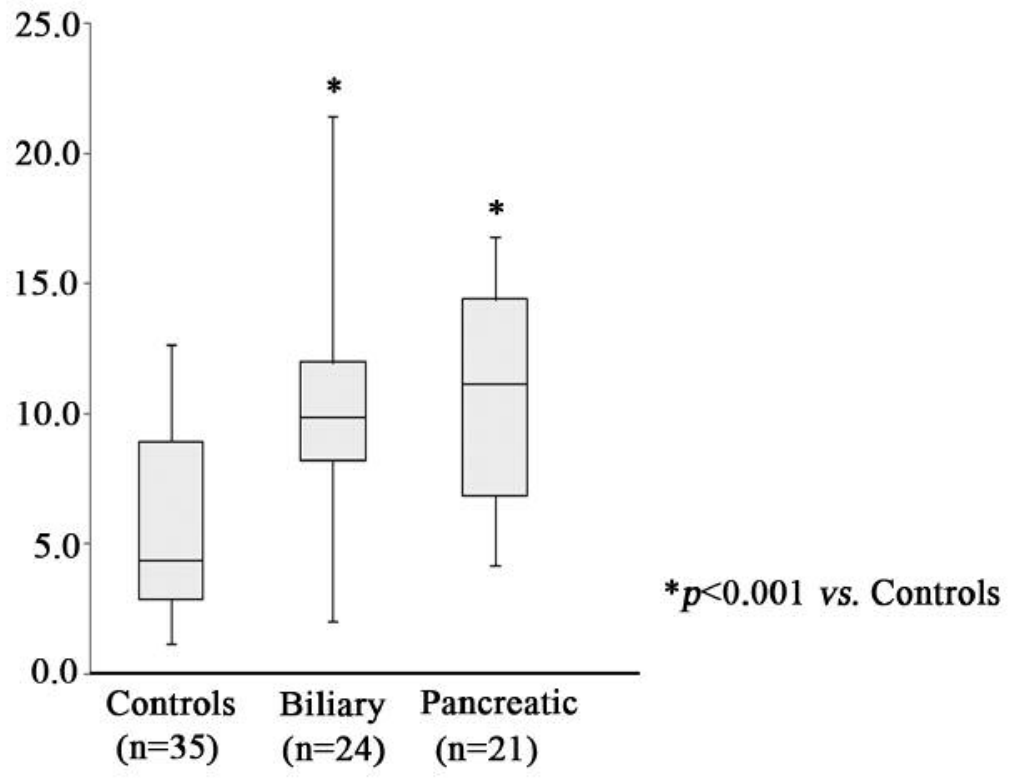

B

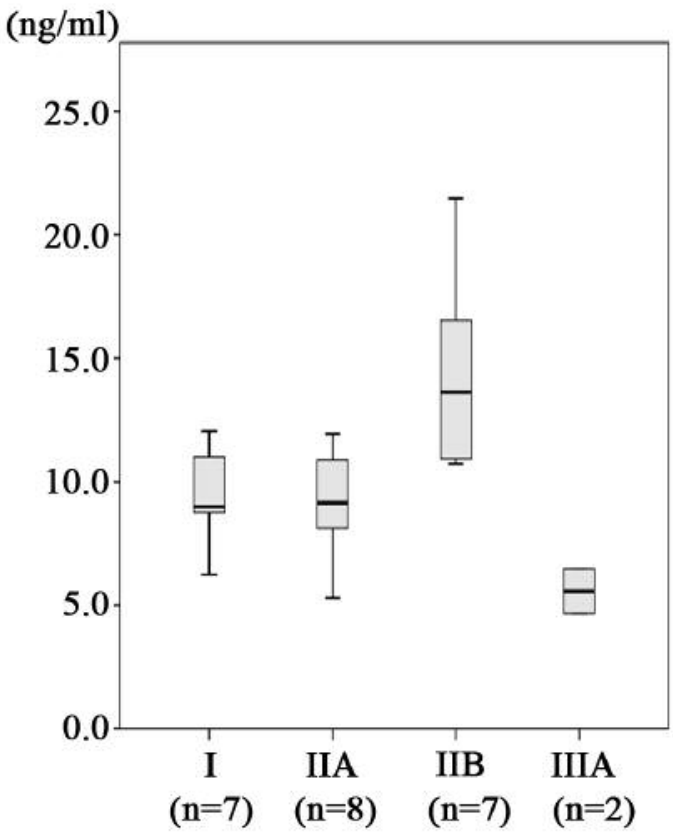

C

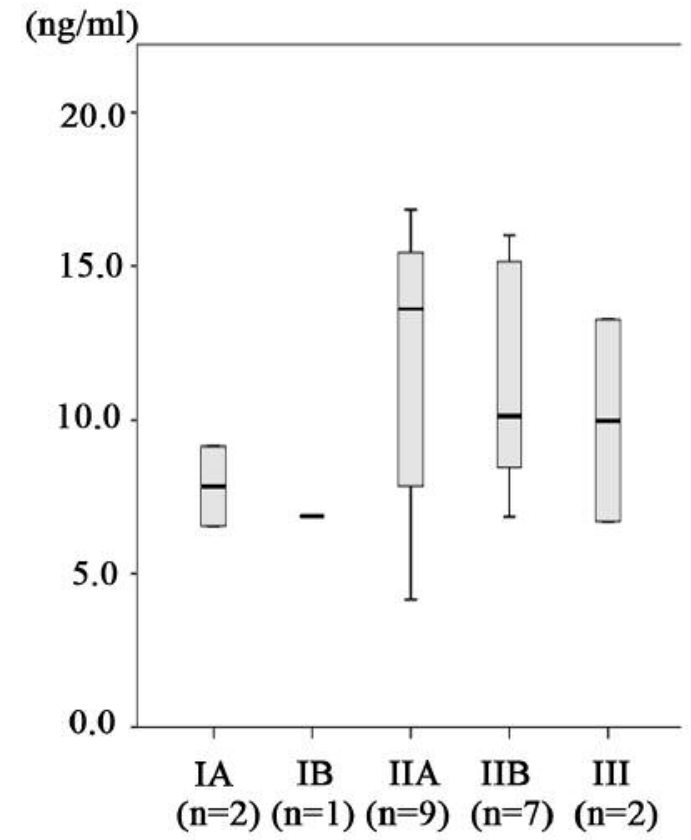

TNM Stage of the disease

\section{TNM Stage of the disease}

Figure 1. Circulating galectin-3 levels. A: Circulating galectin-3 levels in pancreatobiliary cancer. Circulating galectin-3 levels in biliary cancer patients (median=9.8, range $=2.0-21.5$ ) were significantly higher than those (median $=4.2$, range $=1.0-12.5)$ in the healthy controls $(p<0.001)$. Circulating galectin-3 levels in the pancreatic cancer patients (mean=11.1, range $=4.2-16.8$ ) were significantly higher than those of the healthy controls $(p<0.001)$. There was no statistically significant difference of circulating galectin-3 levels between biliary and pancreatic cancer. B. Circulating galectin-3 in biliary cancer according to the TNM stage of the disease. There was no statistically significant difference among each stage. C: Circulating galectin-3 in pancreatic cancer according to the TNM stage of the disease. There is also no statistically significant difference among each stage. 
Table I. Usefulness of circulating galectin-3 as a tumor marker.

\begin{tabular}{|c|c|c|c|c|c|c|}
\hline & & Gal-3 & CEA & CA19-9 & Gal-3+CA19-9 & Gal-3+CEA+CA19-9 \\
\hline \multirow{2}{*}{$\begin{array}{l}\text { Biliary cancer } \\
(n=24)\end{array}$} & Positive number & 22 & 5 & 17 & 23 & 24 \\
\hline & Positive rate $(\%)$ & 91.7 & 20.8 & 70.8 & 95.8 & 100 \\
\hline \multirow{4}{*}{$\begin{array}{l}\text { Pancreatic cancer } \\
(\mathrm{n}=21) \\
\text { Total } \\
(\mathrm{n}=45)\end{array}$} & Positive number & 18 & 5 & 13 & 21 & 21 \\
\hline & Positive rate $(\%)$ & 85.7 & 23.8 & 61.9 & 100 & 100 \\
\hline & Positive number & 40 & 10 & 30 & 44 & 45 \\
\hline & Positive rate $(\%)$ & 88.9 & 22.2 & 66.7 & 97.8 & 100 \\
\hline
\end{tabular}

Gal-3, Galectin-3; CEA, carcinoembryonic antigen; CA19-9, carbohydrate antigen 19-9.

Table II. Evaluation of circulating galectin-3 as a predictor of prognosis.

Biliary cancer $(n=24)$

\begin{tabular}{|c|c|c|c|c|c|c|}
\hline & \multirow{2}{*}{\multicolumn{3}{|c|}{ Univariate analysis }} & & & \\
\hline & & & & \multicolumn{3}{|c|}{ Multivariate analysis } \\
\hline & HR & $95 \% \mathrm{CI}$ & $p$-Value & HR & $95 \% \mathrm{CI}$ & $p$-Value \\
\hline Galectin-3 $(<10.2 \mathrm{ng} / \mathrm{ml} v s . \geq 10.2 \mathrm{ng} / \mathrm{ml})$ & 5.854 & $1.240-27.639$ & 0.026 & 6.197 & $1.187-32.361$ & 0.031 \\
\hline $\mathrm{T}(\mathrm{T} 1+2 v s . \mathrm{T} 3+4)$ & 1.647 & $0.462-5.871$ & 0.442 & 0.762 & $0.090-6.482$ & 0.803 \\
\hline $\mathrm{N}$ (negative $v s$. positive) & 1.546 & $0.443-5.400$ & 0.495 & 1.303 & $0.184-9.204$ & 0.791 \\
\hline Adjuvant chemotherapy (negative $v s$. positive) & 0.699 & $0.197-2.481$ & 0.579 & 0.654 & $0.166-2.574$ & 0.543 \\
\hline
\end{tabular}

HR, Hazard ratio; CI: confidence intervals.

\begin{tabular}{|c|c|c|c|c|c|c|}
\hline & \multicolumn{6}{|c|}{ Pancreatic cancer $(n=21)$} \\
\hline & \multicolumn{3}{|c|}{ Univariate analysis } & \multicolumn{3}{|c|}{ Multivariate analysis } \\
\hline & HR & $95 \% \mathrm{CI}$ & $p$-Value & HR & $95 \% \mathrm{CI}$ & $p$-Value \\
\hline Galectin-3 $(<10.2 \mathrm{ng} / \mathrm{ml} v s . \geq 10.2 \mathrm{ng} / \mathrm{ml})$ & 4.486 & $1.419-14.181$ & 0.011 & 4.559 & $1.176-17.685$ & 0.028 \\
\hline $\mathrm{T}(\mathrm{T} 1+2 v s . \mathrm{T} 3+\mathrm{T} 4)$ & 0.102 & $0.714-42.581$ & 0.442 & 1.680 & $0.174-16.237$ & 0.803 \\
\hline $\mathrm{N}$ (negative $v s$. positive) & 2.393 & $0.812-7.056$ & 0.114 & 1.619 & $0.492-5.323$ & 0.428 \\
\hline Adjuvant chemotherapy (negative $v s$. positive) & 7.963 & $1.027-61.731$ & 0.047 & 5.769 & $0.603-55.156$ & 0.128 \\
\hline
\end{tabular}

HR, hazard ratio; CI: confidence intervals.

(neutrophil: median $=58 \%$, range $=49-90 \%$; NLR: median $=1.8$, range 1.2-12.9) in the low galectin-3 group, and lymphocyte count (median $=14.5 \%$, range $=7.0-34.0 \%, p=0.020$ ) and LMR (median=2.1, range=0.4-3.8, $p=0.008$ ) were significantly lower in the high galectin-3 group than those (lymphocyte count: median $=31.0 \%$, range $=7.0-40.0 \%$; LMR: median $=3.6$, range $=2.1-6.3$ ) in the low galectin-3 group.

\section{Discussion}

In the present study, circulating galectin-3 at the cut-off level of $6.2 \mathrm{ng} / \mathrm{ml}$ had a diagnostic value for pancreatobiliary cancer. Regarding pancreatic cancer, Xie et al. reported on serum galectin-3 levels in 49 pancreatic patients, and assessed the complementary diagnostic value of galectin-3 (23). They concluded that serum galectin-3 is higher in cases with pancreatic cancer than in benign pancreatic disease or healthy people, and that combined determination of serum galectin-3, CEA and CA19-9 may improve the diagnostic power for pancreatic cancer. On the other hand, Koopmann et al. reported on serum galectin-3 levels in 26 biliary cancer patients, and concluded that serum galectin-3 levels did not differ in the biliary cancer group in relation to the controls (25). Alternatively, they concluded that the biliary concentration of the Mac-2-binding protein, which is a galecin-3 binding partner, showed promise as a novel diagnostic marker for biliary cancer. All three reports, including ours, enrolled too few patients to draw a 


\section{A. Biliary cancer}

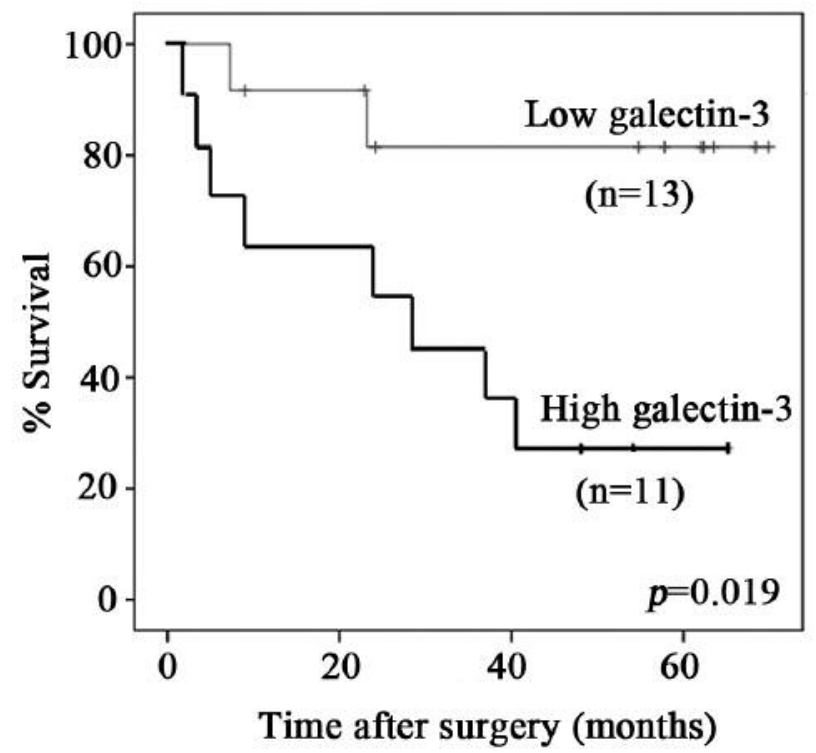

B. Pancreatic cancer

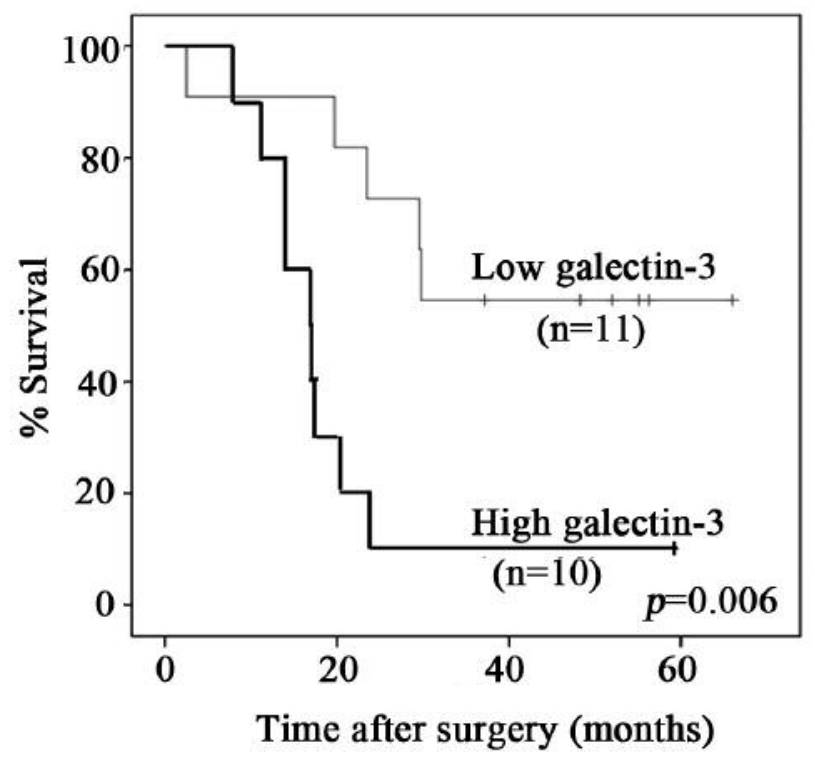

Figure 2. Overall survival of patients. A: Overall survival of the biliary cancer patients ( $n=24)$. The high-galectin-3 group ( $n=11)$ showed a poorer prognosis than the low-galectin-3 group $(n=13)$ in biliary cancer patients $(p=0.019)$. B: Overall survival rate of the pancreatic cancer patients $(n=21)$. The high-galectin-3 group $(n=10)$ showed a poorer prognosis than the low-galectin-3 group $(n=11)$ in pancreatic cancer patients $(p=0.006)$.

Table III. Demographics of patients.

\begin{tabular}{|c|c|c|c|c|c|c|c|c|c|}
\hline & \multicolumn{3}{|c|}{ Total $(n=45)$} & \multicolumn{3}{|c|}{ Biliary cancer $(n=24)$} & \multicolumn{3}{|c|}{ Pancreatic cancer $(n=21)$} \\
\hline & \multicolumn{2}{|c|}{ Galectin-3 } & \multirow[t]{2}{*}{$p$-Value } & \multicolumn{2}{|c|}{ Galectin-3 } & \multirow[t]{2}{*}{$p$-Value } & \multicolumn{2}{|c|}{ Galectin-3 } & \multirow[t]{2}{*}{$p$-Value } \\
\hline & $\begin{array}{l}\text { Low } \\
(\mathrm{n}=24)\end{array}$ & $\begin{array}{l}\text { High } \\
(\mathrm{n}=21)\end{array}$ & & $\begin{array}{l}\text { Low } \\
(\mathrm{n}=13)\end{array}$ & $\begin{array}{l}\text { High } \\
(\mathrm{n}=11)\end{array}$ & & $\begin{array}{l}\text { Low } \\
(\mathrm{n}=11)\end{array}$ & $\begin{array}{c}\text { High } \\
(\mathrm{n}=10)\end{array}$ & \\
\hline Age & $66.6 \pm 12.9$ & $71.6 \pm 7.3$ & 0.256 & $68.2 \pm 12.7$ & $73.6 \pm 6.9$ & 0.256 & $65.4 \pm 13.2$ & $69.0 \pm 7.5$ & 0.349 \\
\hline Gender & & & 0.533 & & & 1.000 & & & 0.381 \\
\hline Male & 14 & 15 & & 8 & 7 & & 6 & 8 & \\
\hline Female & 10 & 6 & & 5 & 4 & & 5 & 2 & \\
\hline $\mathrm{T}$ & & & 0.045 & & & 0.390 & & & 0.090 \\
\hline $\mathrm{T} 1+2$ & 14 & 6 & & 10 & 6 & & 4 & 0 & \\
\hline $\mathrm{T} 3+4$ & 10 & 15 & & 3 & 5 & & 7 & 10 & \\
\hline $\mathrm{N}$ & 0.688 & & 1.000 & & & 1.000 & & & \\
\hline- & 14 & 11 & & 8 & 6 & & 6 & 5 & \\
\hline+ & 10 & 10 & & 5 & 5 & & 5 & 5 & \\
\hline Stage & & & 0.611 & & & 0.482 & & & 1.000 \\
\hline $\mathrm{I}+\mathrm{II}$ & 21 & 20 & & 11 & 11 & & 10 & 9 & \\
\hline III & 3 & 1 & & 2 & 0 & & 1 & 1 & \\
\hline Histology & & & 0.045 & & & 0.414 & & & 0.183 \\
\hline well & 14 & 6 & & 8 & 4 & & 6 & 2 & \\
\hline Mod + Por & 10 & 15 & & 5 & 7 & & 5 & 8 & \\
\hline Chemo & & & 0.807 & & & 0.444 & & & 0.311 \\
\hline- & 10 & 8 & & 6 & 7 & & 4 & 1 & \\
\hline+ & 14 & 13 & & 7 & 4 & & 7 & 9 & \\
\hline
\end{tabular}

Well, Well differentiated adenocarcinoma; Mod, moderately differentiated adenocarcinoma; Por, poorly differentiated adenocarcinoma; Chemo, adjuvant chemotherapy. 


\section{A. Biliary cancer $(n=24)$}

RBP (mg/dl)

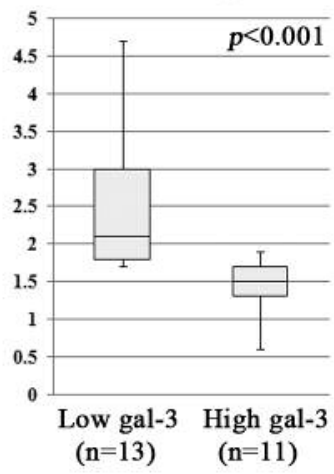

TTR (mg/dl)

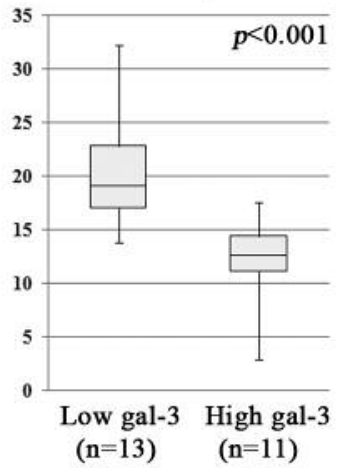

$\mathrm{TF}$ (mg/dl)

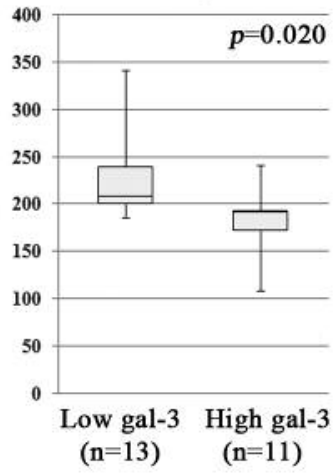

Albumin (mg/dl)

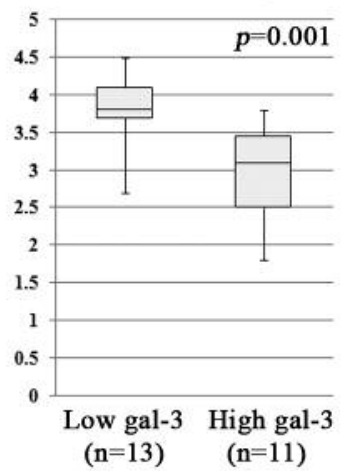

\section{B. Pancreatic cancer $(n=21)$}

Neutrophil (\%)

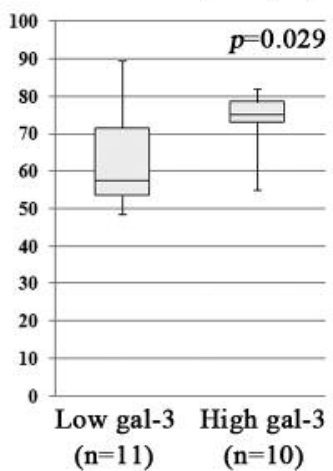

Lymphocyte (\%)

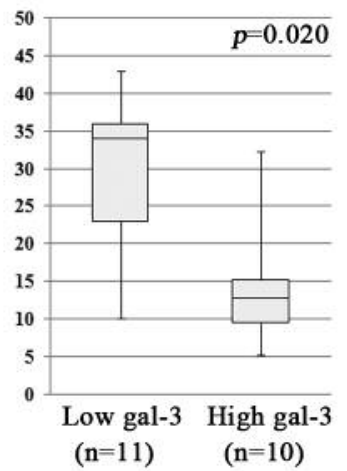

NLR

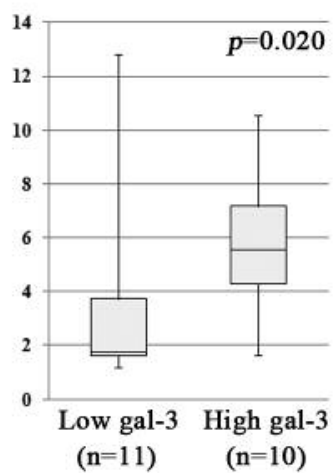

LMR

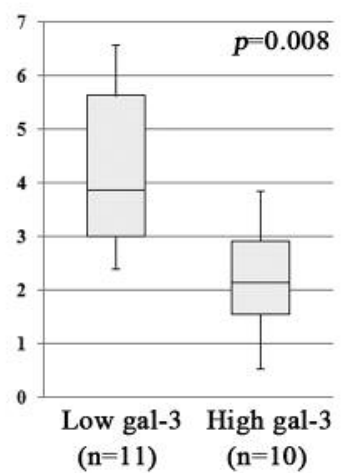

Figure 3. Inflammatory and nutritional parameters according to galectin-3 levels in the subgroup analysis. A: In the analysis on the 24 biliary cancer patients, retinol binding protein $(p<0.001)$, transthyretin $(p<0.001)$, transferrin $(p=0.020)$, and albumin $(p=0.001)$ were significantly lower in the high-galectin-3 group (High gal-3) ( $n=11)$ than those in the low-galectin-3 group (Low gal-3) ( $n=13)$. B: In the analysis on the 21 pancreatic cancer patients, neutrophil count $(p=0.029)$ and neutrophil-to-lymphocyte ratio $(p=0.020)$ were significantly higher in the high-galectin-3 group (High gal-3) ( $n=10)$ than those in the low-galectin-3 group (Low gal-3) ( $n=11)$, while lymphocyte count ( $p=0.020)$ and lymphocyte-to-monocyte ratio ( $p=0.008)$ were significantly lower in the high-galectin-3 group than those in the low-galectin-3 group. RBP, Retinol binding protein; TTR, transthyretin; TF, transferrin; NLR, neutrophil-to-lymphocyte ratio; LMR, lymphocyte-to-monocyte ratio.

conclusion on the usefulness of galectin-3 as a novel biomarker to discriminate pancreatobiliary cancer from normal controls.

On the other hand, there have been no reports concerning the relationship between circulating galectin-3 and its prognostic value in pancreatobiliary cancer. Circulating galectin-3 levels were also able to predict the patients' overall survival of pancreatobiliary cancer patients at the cutoff level of $10.2 \mathrm{ng} / \mathrm{ml}$ in the present study. Analysis of overall survival using the Kaplan-Meier method revealed that the high galectin-3 group showed a poorer prognosis than the low galectin-3 group. Furthermore, circulating galectin-3 $\geq 10.2 \mathrm{ng} / \mathrm{ml}$ was an independent prognostic factor in both biliary and pancreatic cancer by multivariate analyses in a Cox proportional hazard model. Our previous report examined galectin-3 expression in 37 extrahepatic biliary cancer patients. The incidence of cases that were galectin- 3 positive for more than $50 \%$ of the tumor cells was 25 out of $37(67.6 \%)$ (26). In our preliminary data, the incidence of cases that were galectin-3 positive for more than $50 \%$ of the tumor cells was 17 out of 25 cases $(68.0 \%$ ) (data not shown). The sources of circulating galectin-3 are not only tumor cells, but also macrophages, mast cells, and eosinophils (11, 12). The circulating level of galectin-3 is not always representative of the expression level of galectin-3 in the tumor microenvironment. However, the incidence of patients 
with T3 or T4 was statistically higher in the high galectin-3 group than in the low galectin-3 group in this study. Thus, deeper infiltration presented as $\mathrm{T} 3$ or $\mathrm{T} 4$ might cause invasion into the tumor surrounding vessels, resulting in increasing circulating galectin-3 levels.

On the other hand, pancreatic cancer is one of the most formidable malignancies due to its chemoresistance. Despite the development of combination therapy, such as nabpaclitaxel with gemcitabine and FOLFIRINOX, patient outcomes remain unsatisfactory $(27,28)$. Thus, novel molecular targets are urgently required to overwhelm this type of cancer $(29,30)$. We previously reported that silencing of galectin-3 in pancreatic cancer cells suppressed their ability of migration and invasion, and increased sensitivity against chemotherapeutic drugs $(31,32)$. Although it remains to be elucidated that circulating galectin-3 could affect chemosensitivity, a certain adjuvant therapy may improve prognostic outcome of patients with high galectin-3 levels.

In subgroup analyses regarding biliary cancer, higher circulating galectin-3 was associated with lower levels of RBP, TTR, and TF. Malnutrition in cancer-loaded patients obviously leads to poor prognosis. Thus, the poorer prognosis of the biliary cancer patients with high galectin- 3 might be attributed to this association with malnutrition. On the other hand, regarding pancreatic cancer, higher circulating galectin-3 correlated with higher neutrophil count, higher NLR, lower lymphocyte count, and lower LMR. Higher neutrophil count, higher NLR and lower LMR have been reported to be independent prognostic markers in pancreatic cancer patients (33). Systemic chronic inflammation has been reported to have a role in the suppression of tumor immunity $(34,35)$. Taken together, higher levels of circulating galectin-3 may play a role in inducing malnutrition and continuous inflammation, resulting in the immunosuppressive status of hosts.

The present study is the first report on the relationship between circulating galectin-3, nutritional or inflammatory parameters, and prognosis in pancreatobiliary cancer patients. However, there are some limitations in this study as well. The major limitation is the small sample size, with retrospective analyses. Secondly, we did not analyze timedependent changes of serum galectin-3. Thirdly, we did not examine the galectin-3 expression levels in the resected specimen to estimate the relationship between circulating galectin-3 and expression levels of galectin-3 in tumor cells.

In conclusion, our study showed that circulating galectin$3 \mathrm{had}$ a diagnostic value at the cutoff level of $6.2 \mathrm{ng} / \mathrm{ml}$. In addition, circulating galectin-3 was a predictor of patient overall survival at the cutoff level of $10.3 \mathrm{ng} / \mathrm{ml}$. Furthermore, circulating galectin- $3 \geq 10.3 \mathrm{ng} / \mathrm{ml}$ was an independent prognostic marker in pancreatobiliary cancer. Association of circulating galectin-3 with malnutrition and pro-inflammation might cause poor prognosis in pancreatobiliary cancer patients.

\section{Conflicts of Interest}

The Authors declare no conflicts of interest.

\section{Acknowledgements}

This work was partly supported by the Grants-in-Aid for Scientific Research from the Japan Society for the Promotion of Science (16K10605).

\section{References}

1 Barr Fritcher EG, Voss JS, Brankley SM, Campion MB, Jenkins SM, Keeney ME, Henry MR, Kerr SM, Chaiteerakij R, Pestova EV, Clayton AC, Zhang J, Roberts LR, Gores GJ, Halling KC and Kipp BR: An Optimized Set of Fluorescence In Situ Hybridization Probes for Detection of Pancreatobiliary Tract Cancer in Cytology Brush Samples. Gastroenterology 149: 1813-1824, 2015.

2 Siegel RL, Miller KD and Jemal A: Cancer statistics, 2016. CA Cancer J Clin 66: 7-30, 2016.

3 Hori M, Matsuda T, Shibata A, Katanoda K, Sobue T, Nishimoto $\mathrm{H}$ and Japan Cancer Surveillance Research Group: Cancer incidence and incidence rates in Japan in 2009: a study of 32 population-based cancer registries for the Monitoring of Cancer Incidence in Japan (MCIJ) project. Jpn J Clin Oncol 45: 884$891,2015$.

4 Akahani S, Nangia-Makker P, Inohara H, Kim HR and Raz A: Galectin-3: a novel antiapoptotic molecule with a functional BH1 (NWGR) domain of Bcl-2 family. Cancer Res 57: 52725276, 1997.

5 Danguy A, Camby I and Kiss R: Galectins and cancer. Biochim Biophys Acta 1572: 285-293, 2002.

6 Davidson PJ, Davis MJ, Patterson RJ, Ripoche MA, Poirier F and Wang JL: Shuttling of galectin-3 between the nucleus and cytoplasm. Glycobiology 12: 329-337, 2002.

7 Lin HM, Pestell RG, Raz A and Kim HR: Galectin-3 enhances cyclin $\mathrm{D}(1)$ promoter activity through SP1 and a cAMPresponsive element in human breast epithelial cells. Oncogene 21: 8001-8010, 2002.

8 Funasaka T, Raz A and Nangia-Makker P: Galectin-3 in angiogenesis and metastasis. Glycobiology 24: 886-891, 2014.

9 Dagher SF, Wang JL and Patterson RJ: Identification of galectin3 as a factor in pre-mRNA splicing. Proc Natl Acad Sci USA 92: 1213-1217, 1995.

10 Newlaczyl AU and Yu LG: Galectin-3-a jack-of-all-trades in cancer. Cancer Lett 313: 123-128, 2011.

11 de Boer RA, van VeldhuisenDJ, Gansevoort RT, Muller Kobold AC, van Gilst WH, Hillege HL, Bakker SJL and van der Harst P: The fibrosis marker galectin-3 and outcome in the general population. J Intern Med 272: 55-64, 2012.

12 Iurisci I, Tinari N, Natoli C, Angelucci D, Cianchetti E and Iacobelli S: Concentrations of galectin-3 in the sera of normal controls and cancer patients. Clin Cancer Res 6: 1389-1393, 2000.

13 Vereecken P, Zouaoui Boudjeltia K, Debray C, Awada A, Legssyer I, Sales F, Petein M, Vanhaeverbeek M, Ghanem G and Heenen M: High serum galectin-3 in advanced melanoma: preliminary results. Clin Exp Dermatol 31: 105-109, 2006. 
14 Iacovazzi PA, Notarnicola M, Caruso MG, Guerra V, Frisullo S, Altomare DF and Correale M: Serum levels of galectin-3 and its ligand $90 \mathrm{k} / \mathrm{mac}-2 \mathrm{bp}$ in colorectal cancer patients. Immunopharmacol Immunotoxicol 32: 160-164, 2010.

15 Chen C, Duckworth CA, Zhao Q, Pritchard DM, Rhodes JM and Yu LG: Increased circulation of galectin-3 in cancer induces secretion of metastasis-promoting cytokines from blood vascular endothelium. Clin Cancer Res 19: 1693-1704, 2013.

16 Cheng D, Liang B and Li Y: Serum galectin-3 as a potential marker for gastric cancer. Med Sci Monit 21: 755-760, 2015.

17 Sakaki M, Oka N, Nakanishi R, Yamaguchi K, Fukumori T and Kanayama HO: Serum level of galectin-3 in human bladder cancer. J Med Invest 55: 127-132, 2008.

18 Gendy HE, Madkour B, Abdelaty S, Essawy F, Khattab D, Hammam O and Nour HH: Diagnostic and Prognostic Significance of Serum and Tissue Galectin 3 Expression in Patients with Carcinoma of the Bladder. Curr Urol 7: 185-190, 2014.

19 Saussez S, Lorfevre F, Lequeux T, Laurent G, Chantrain G, Vertongen F, Toubeau G, Decaestecker C and Kiss R: The determination of the levels of circulating galectin-1 and -3 in HNSCC patients could be used to monitor tumor progression and/or responses to therapy. Oral Oncol 44: 86-93, 2008.

20 Ulu M, Alacacioglu A, Yuksel E, Pamukk BO, Bozkaya G, Ari A, Yuksel A, Sop G and Alacacioglu I: Prognostic significance of serum galectin-3 levels in patients with hepatocellular cancer and chronic viral hepatitis. Saudi J Gastroenterol 21: 47-50, 2015.

21 Išić T, Savin S, Cvejić D, Marečko I, Tatić S, Havelka M and Paunović I: Serum Cyfra 21.1 and galectin-3 protein levels in relation to immunohistochemical cytokeratin 19 and galectin-3 expression in patients with thyroid tumors. J Cancer Res Clin Oncol 136: 1805-1812, 2010.

22 Yılmaz E, Karşıdağ T, Tatar C and Tüzün S: Serum Galectin-3: diagnostic value for papillary thyroid carcinoma. Ulus Cerrahi Derg 31: 192-196, 2015.

23 Xie L, Ni WK, Chen XD, Xiao MB, Chen BY, He S, Lu CH, Li $\mathrm{XY}$, Jiang $\mathrm{F}$ and $\mathrm{Ni} \mathrm{RZ}$ : The expressions and clinical significances of tissue and serum galectin-3 in pancreatic carcinoma. J Cancer Res Clin Oncol 138: 1035-1043, 2012.

24 Wittekind C: Hepatobiliary section. In: TNM classification of malignant tumours (Brierley JD, Gospodarowicz MK, Wittekind C (eds.). Oxford, Wiley-Blackwell, pp. 80-95, 2017.

25 Koopmann J, Thuluvath PJ, Zahurak ML, Kristiansen TZ, Pandey A, Schulick R, Argani P, Hidalgo M, Iacobelli S, Goggins M and Maitra A: Mac-2-binding protein is a diagnostic marker for biliary tract carcinoma. Cancer 101: 1609-1615, 2004.
26 Shimura T, Kofunato Y, Okada R, Yashima R, Koyama Y, Araki $\mathrm{K}$, Kuwano $\mathrm{H}$ and Takenoshita $\mathrm{S}$ : Intranuclear accumulation of galectin-3 is an independent prognostic factor for patients with distal cholangiocarcinoma. Oncol Lett 14: 819-829, 2017.

27 Vogel A, Pelzer U, Salah-Eddin AB and Köster W: First-line nab-paclitaxel and gemcitabine in patients with metastatic pancreatic cancer from routine clinical practice. In Vivo 28: 1135-1140 2014.

28 Ploquin A, Truant S, Piessen G, Vuagnat P, Baldini C, Cattan S and Hebbar M: Locally advanced or metastatic pancreatic adenocarcinoma: easily available factors of predictive prolonged survival under gemcitabine. In Vivo 31: 731-735, 2017.

29 Narayanan R: Phenome-genome association studies of pancreatic cancer: new targets for therapy and diagnosis. Cancer Genomics Proteomics 12: 9-20, 2015.

30 Baron B, Fujioka T, Kitagawa T, Maehara S, Maehara Y, Nakamura $\mathrm{K}$ and Kuramitsu Y: Comparative proteomic analysis of two stress-management strategies in pancreatic cancer. Cancer Genomics Proteomics 12: 83-88, 2015.

31 Kobayashi T, Shimura T, Yajima T, Kubo N, Araki K, Tsutsumi S, Suzuki H, Kuwano H and Raz A: Transient gene silencing of galedctin-3 suppresses pancreatic cancer cell migration and invasion through degradation of $\beta$-catenin. Int J Cancer 129: 2775-2786, 2011.

32 Kobayashi T, Shimura T, Yajima T, Kubo N, Araki K, Wada W, Tsutsumi S, Suzuki H, Kuwano H and Raz A: Transient silencing of galectin-3 expression promotes both in vitro and in vivo drug-induced apoptosis of human pancreatic carcinoma cells. Clin Exp Metastasis 28: 367-376, 2011.

33 Qi Q, Geng Y, Sun M, Wang P and Chen Z: Clinical implications of systemic inflammatory response markers as independent prognostic factors for advanced pancreatic cancer. Pancreatology 15: 145-150, 2015.

34 Blackwill $\mathrm{F}$ and Mantovani A: Cancer and inflammation: implications for pharmacology and therapeutics. Clin Pharmacol Ther 87: 401-406, 2010.

35 Coussens LM and Werb Z: Inflammation and cancer. Nature 420: 860-867, 2002. 